\title{
Frequency Beam Steering Antenna for Millimeter Wave Checkpoint Scanners
}

\author{
Mohammad Alibakhshikenari ${ }^{1}$, Bal S. Virdee ${ }^{2}$, Aurora Andújar ${ }^{3}$, Jaume Anguera ${ }^{3,4}$, and Ernesto Limiti ${ }^{1}$ \\ ${ }^{1}$ Electronics Engineering Department, University of Rome “Tor Vergata”, ITALY \\ alibakhshikenari@ing.uniroma2.it, limiti@ing.uniroma2.it \\ ${ }^{2}$ Center for Communications Technology, Faculty of Life Sciences and Computing, London Metropolitan University, UK \\ b.virdee@londonmet.ac.uk \\ ${ }^{3}$ Technology Department, Fractus, SPAIN \\ aurora.andujar@fractus.com \\ ${ }^{4}$ Electronics and Communications Department, Universitat Ramon Llull, SPAIN \\ jaumean@salleurl.edu
}

\begin{abstract}
Millimeter wave scanners are the most prevalent nearfield imaging passenger security systems. The paper describes a planar antenna to replace multiple antennas used in millimeter wave security checkpoints. The antenna is compact in size and capable of frequency scanning over an angle of $-50^{\circ}$ to $+15^{\circ}$. It operates across FCC's frequency range of $24.25 \mathrm{GHz}$ to $30 \mathrm{GHz}$ for full-body airport scanners. The antenna structure, which is based on cheap microstrip technology, is simple to design and fabricate. The proposed antenna consists of a linear array of $1 \times 4$ radiating elements. The measured results conforms the antenna exhibits a maximum gain and radiation efficiency measured are $6.75 \mathrm{dBi}$ and $82.34 \%$, respectively, at $27.5 \mathrm{GHz}$.
\end{abstract}

Keywords- Antenna, planar, imaging, checkpoint, beam scanning, millimeter wave antenna, imaging systems

\section{INTRODUCTION}

Millimeter wave scanner is a whole body imaging device used for detecting objects concealed underneath a person's clothing using a form of electromagnetic radiation [1]-[4]. Typical uses for this technology include detection of items for commercial loss prevention, smuggling and screening at government buildings and airport security checkpoints. Several countries employ the scanners for security screening. A competing technology is backscatter X-ray, which is an ionizing radiation with mutagenic potential.

Millimeter wave scanners themselves come in two varieties, i.e. active and passive. Active scanners direct millimeter wave energy at the subject and then interpret the reflected energy. Passive systems create images using only ambient radiation and radiation emitted from the human body or objects. With active scanners, the millimeter wave is transmitted from two antennas simultaneously as they rotate around the body. The wave energy reflected back from the body or other objects on the body is used to construct a threedimensional image, which is displayed on a remote monitor for analysis. Under a Federal Communications Commission (FCC) waiver full-body airport scanners can use repeated sweeps over the range $24.25-30 \mathrm{GHz}$ to detect objects hidden underneath clothes.

The antenna is a main component in millimeter wave scanners used at airport security checkpoints [1]-[4]. Multiple antennas are employed in the scanner which requires a large booth to accommodate it. In this paper, a compact antenna design is described for operation over $24.25 \mathrm{GHz}$ to $30 \mathrm{GHz}$ with beam steering capability for ultra-wideband imaging of a human body. The proposed antenna should enable the development of small and portable scanners. It is well known and understood that microstrip antennas enable the implementation of miniaturized antennas however the major disadvantage of microstrip antennas are narrow bandwidth and low efficiency performance. To overcome these drawbacks, we have proposed a microstrip antenna implemented using an array configuration. The realized antenna has a frequency bandwidth of $23.10 \mathrm{GHz}$ to $32.50 \mathrm{GHz}$, which is greater than the desired range. Furthermore, the effective aperture of the array structure is increased resulting in improved antenna gain and radiation efficiency performance.

\section{The Proposed Millimeter Wave Antenna}

Configuration of the proposed antenna is shown in Fig. 1. It consists of a linear array consisting of $1 \times 4$ radiating elements, comprising $\mathrm{H}$-shaped stub loaded with two $\mathrm{T}$ shaped auxiliary stubs. A common feedline connects the linear array which is terminated with a $50 \mathrm{Ohm}$ load. The antenna design was constructed on Rogers RT/Duroid 5880 substrate with dielectric constant $\left(\varepsilon_{r}\right)$ of 2.2 , loss tangent $(\tan \delta)$ of 0.0004 , and height $(\mathrm{h})$ of $1.6 \mathrm{~mm}$. The optimized structural parameters of the antenna are listed in Table I.

Physical dimensions of the antenna are $42.2 \times 7.7 \times 1.6 \mathrm{~mm}^{3}$, which corresponds to an electrical size of $3.25 \lambda_{0} \times 0.59 \lambda_{0} \times 0.12 \lambda_{0}$, where $\lambda_{0}$ represents free space wavelength at $23.10 \mathrm{GHz}$. Fig. 2 shows the simulated frequency bandwidth of the optimized antenna is $10.10 \mathrm{GHz}$ (from $22.70-32.80 \mathrm{GHz}$ ) for a reflection coefficient of $\mathrm{S}_{11} \leq$ $10 \mathrm{~dB}$, which corresponds to a fractional bandwidth of $36.39 \%$. The actual measured bandwidth of the antenna is $9.40 \mathrm{GHz}$ (from $23.10-32.50 \mathrm{GHz}$ ), which corresponds to a fractional bandwidth of $33.81 \%$. Simulation analysis was done using High Frequency Structure Simulator (HFSS ${ }^{\mathrm{TM}}$ ). There is reasonably good agreement between the simulated and measured results. These results confirm the proposed microstrip antenna covers the frequency range $(24.25 \mathrm{GHz}$ to $30.00 \mathrm{GHz}$ ) needed for millimeter wave scanners. 


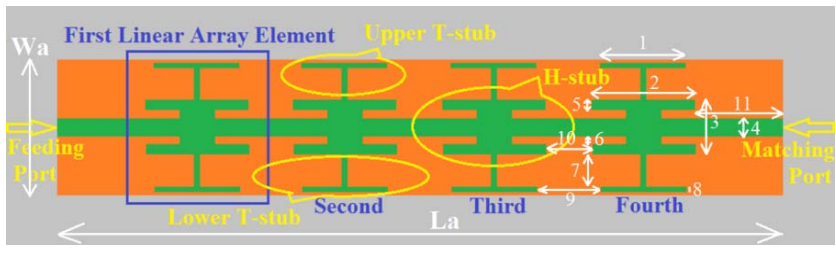

(a) Layout of the proposed antenna

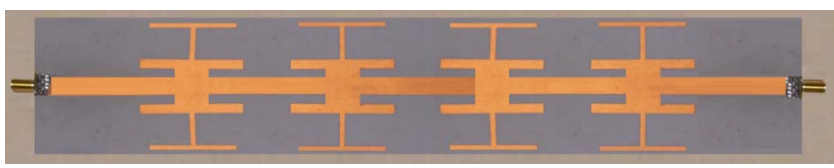

(b) Fabricated prototype antenna

Fig. 1. Geometry of the proposed antenna.

TABle I. Antenna Structural Dimensions Defined IN Fig. 1a (IN MiLLIMETERS)

\begin{tabular}{|c|c|c|c|c|c|c|c|}
\hline Number (\#) & $\# 1$ & $\# 2$ & $\# 3$ & $\# 4$ & $\# 5$ & $\# 6$ & $\# 7$ \\
\hline Dimensions & 5 & 6 & 3.3 & 1.25 & 0.6 & 0.4 & 2.2 \\
\hline
\end{tabular}

\begin{tabular}{|c|c|c|c|c|c|c|c|}
\hline Number (\#) & $\# 8$ & $\# 9$ & $\# 10$ & $\# 11$ & $\# L a$ & $\# W a$ & $\# h$ \\
\hline Dimensions & 0.4 & 3.6 & 2.6 & 5.2 & 42.2 & 7.7 & 1.6 \\
\hline
\end{tabular}

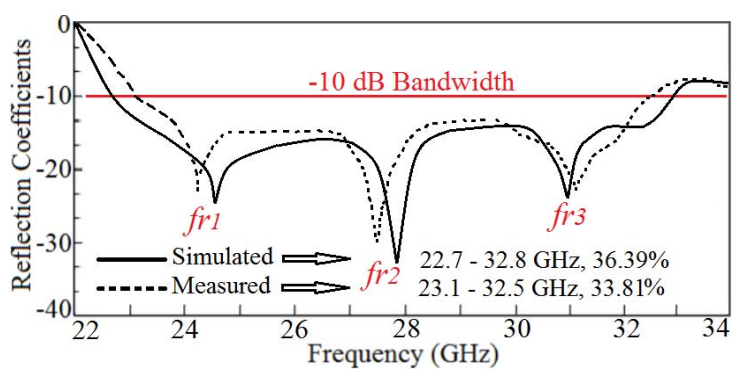

Fig. 2. Simulated and measured reflection coefficient response $\left(\mathrm{S}_{11}<-10 \mathrm{~dB}\right)$.

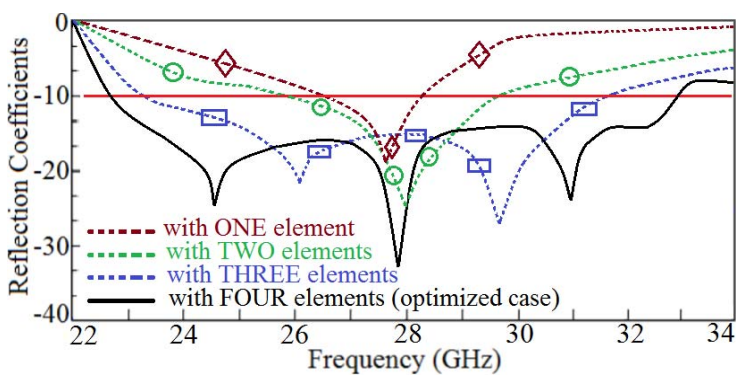

Fig. 3. Parametric study showing how the number of array elements affects the antenna's bandwidth performance.

Results of the parametric study on the antenna bandwidth are shown in Fig. 3. It is evident from this study that the larger the number of elements in the array the greater the frequency bandwidth of the antenna. The array elements essentially introduce resonance frequencies thereby enhancing the antenna's operational bandwidth and matching impedance.
In addition to meeting the goals of miniaturized dimensions and frequency bandwidth, the radiation characteristics of the antenna is important. The antenna's gain and radiation efficiency response are shown in Fig. 4. The results show the simulated gain and efficiency vary from 3.50 $\mathrm{dBi}$ to $7 \mathrm{dBi}$ and $45.5 \%$ to $85.1 \%$, respectively, within the frequency range of $22.7 \mathrm{GHz}$ to $32.8 \mathrm{GHz}$. The measured gain and efficiency vary from $3.35 \mathrm{dBi}$ to $6.75 \mathrm{dBi}$ and $40.85 \%$ to $82.34 \%$, respectively, in the frequency range of $23.1 \mathrm{GHz}$ to $32.5 \mathrm{GHz}$. The maximum measured gain and radiation efficiency are $6.75 \mathrm{dBi}$ and $82.34 \%$, respectively, at $27.5 \mathrm{GHz}$.

Fig. 5 shows the parametric study on how the antenna's gain and radiation efficiency are affected by the number of array elements. By increasing the number of array elements in the linear configuration, shown in Fig. 1, the antenna's physical dimensions will inevitably increase. By doing this the effective aperture of the antenna also increases too thus enhancing the antenna's radiation characteristics, as shown in Fig. 5. The final antenna design consists of an array with 4 elements to satisfy the scanners bandwidth requirements (24.25 $\mathrm{GHz}$ to $30 \mathrm{GHz})$.

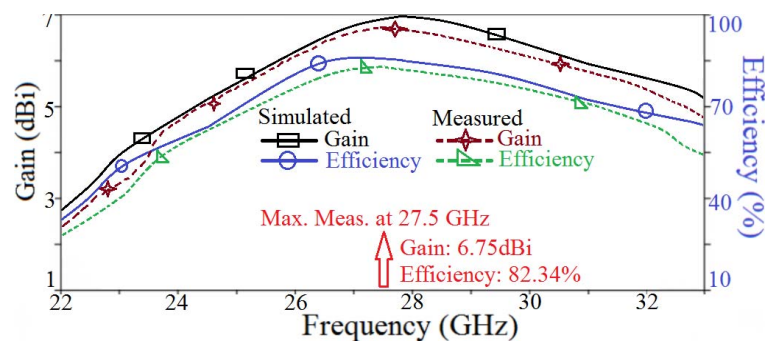

Fig. 4. The proposed antenna's gain and radiation efficiency response.

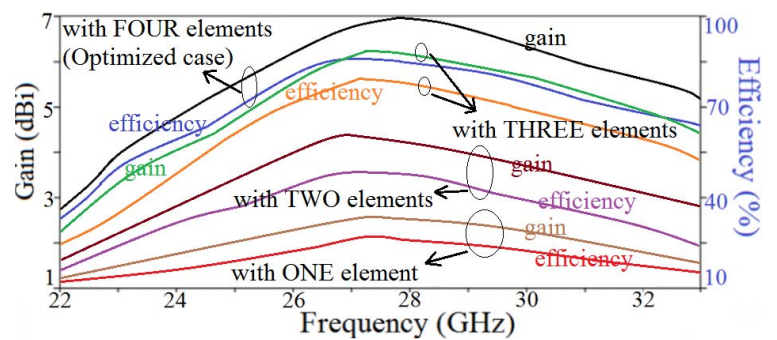

Fig. 5. Parametric study showing the effect of number of array elements on the antenna's gain and efficiency performance.

The antenna radiation patterns are shown in Fig. 6. Clearly, the antenna is capable of scanning from $-50^{\circ}$ to $+15^{\circ}$ over its operational frequency bandwidth. The antenna's backfire, broadside and endfire radiations occur at $f_{r_{1}}=24.25$ $\mathrm{GHz}, f_{r_{2}}=27.50 \mathrm{GHz}$, and $f_{r_{3}}=31.10 \mathrm{GHz}$, respectively. The sidebands associated with the antenna are less than $-20 \mathrm{~dB}$.

Simulated and measured performance parameters of the antenna are given in Table II. There is generally good agreement between the simulated and measured results. The proposed antenna is compact in size, operates over the frequency band from $23.1 \mathrm{GHz}$ to $32.5 \mathrm{GHz}$, and is capable of scanning over a wide angle from $-50^{\circ}$ to $+15^{\circ}$. 
TABLE II. ANTENNA's PERFORMANCE PARAMETERS

\begin{tabular}{|c|c|c|c|c|c|c|}
\hline Dimensions & \multicolumn{6}{|c|}{$42.2 \times 7.7 \times 1.6 \mathrm{~mm}^{3}$ and $3.25 \lambda_{0} \times 0.59 \lambda_{0} \times 0.12 \lambda_{0}$ where $\lambda_{0}$ is free space wavelength at $23.10 \mathrm{GHz}$} \\
\hline \multirow{3}{*}{ Bandwidth } & \multicolumn{6}{|c|}{ Simulated: $10.10 \mathrm{GHz}$ (from $22.70-32.80 \mathrm{GHz}$ ) / fractional bandwidth $=36.39 \%$} \\
\hline & \multicolumn{6}{|c|}{ Measured: $9.40 \mathrm{GHz}$ (from $23.10-32.50 \mathrm{GHz}$ ) / fractional bandwidth $=33.81 \%$} \\
\hline & \multirow[t]{2}{*}{ Simulated } & 3.50 & 5.12 & 7.00 & 5.95 & 5.22 \\
\hline \multirow[t]{3}{*}{ Gain (dBi) } & & (a) $22.7 \mathrm{GHz}$ & (a) $24.50 \mathrm{GHz}$ & (a) $27.8 \mathrm{GHz}$ & (a) $30.95 \mathrm{GHz}$ & (a) $32.8 \mathrm{GHz}$ \\
\hline & \multirow[t]{2}{*}{ Measured } & 3.35 & 5.00 & 6.75 & 5.73 & 5.10 \\
\hline & & (a) $23.10 \mathrm{GHz}$ & @ $24.25 \mathrm{GHz}$ & (a) $27.5 \mathrm{GHz}$ & (a) $31.10 \mathrm{GHz}$ & (a) $32.50 \mathrm{GHz}$ \\
\hline \multirow{4}{*}{ Efficiency $(\%)$} & \multirow[t]{2}{*}{ Simulated } & 45.50 & 63.40 & 85.10 & 72.81 & 65.47 \\
\hline & & $@ 22.7 \mathrm{GHz}$ & @ $24.50 \mathrm{GHz}$ & @ $27.8 \mathrm{GHz}$ & (a) $30.95 \mathrm{GHz}$ & (@) $32.8 \mathrm{GHz}$ \\
\hline & \multirow[t]{2}{*}{ Measured } & 40.85 & 60.01 & 82.34 & 70.10 & 61.70 \\
\hline & & (a) $23.10 \mathrm{GHz}$ & (a) $24.25 \mathrm{GHz}$ & (a) $27.5 \mathrm{GHz}$ & (a) $31.10 \mathrm{GHz}$ & (a) $32.50 \mathrm{GHz}$ \\
\hline
\end{tabular}

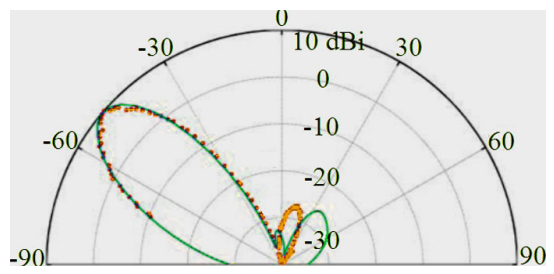

(a) $f_{r_{1}}=24.25 \mathrm{GHz}$

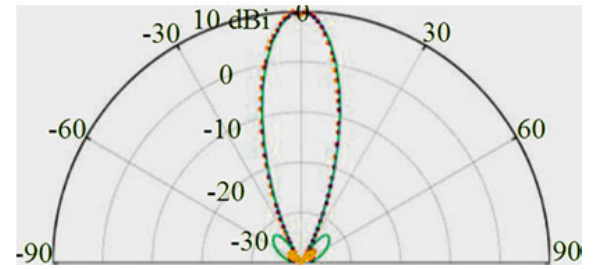

(b) $f_{r_{2}}=27.50 \mathrm{GHz}$

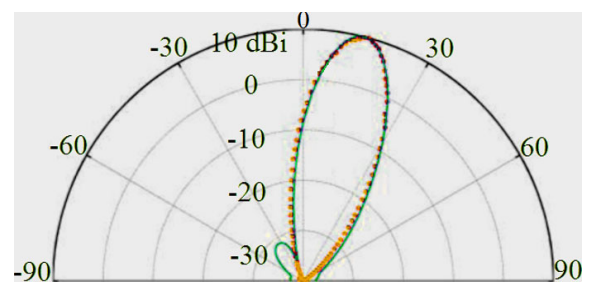

(c) $f_{r_{3}}=31.10 \mathrm{GHz}$

Fig. 6. Antenna's simulated and measured radiation patterns: (a) backfire radiation patterns at $f_{r_{1}}=24.25 \mathrm{GHz}$, (b) broadside radiation pattern at $f_{r_{2}}=$ $27.50 \mathrm{GHz}$, and (c) endfire radiation pattern $f_{r_{3}}=31.10 \mathrm{GHz}$. Dashed lines and solid lines present the simulated and measured patterns, respectively.

\section{CONCLUSION}

A novel millimeter wave antenna has been demonstrated to exhibit beam scanning over an angle of $-50^{\circ}$ to $+15^{\circ}$, and it operates over a frequency range of $23.10 \mathrm{GHz}$ to $32.50 \mathrm{GHz}$. The planar antenna design consists of a linear array consisting of $1 \times 4$ radiating elements. The parametric study showed the antenna's characterizing parameters (impedance bandwidth, gain and radiation efficiency) are significantly enhanced by simply increasing the number elements in the array. The measured results conforms the antenna exhibits a maximum gain and radiation efficiency measured are $6.75 \mathrm{dBi}$ and $82.34 \%$, respectively, at $27.5 \mathrm{GHz}$. The singular antenna can be adapted to replace multiple antennas employed in airport security checkpoint scanners. This should result in a portable scanner system.

\section{REFERENCES}

[1] A.Kazemipour, T. K. Ostmann, T. Schrader, D. Allal, M. Charles, L. Zilberti, M. Borsero, O. Bottauscio, M. Chiampi, "Saftey checkpoints," IEEE Micro. Mag., vol. 17, No. 6, 2016, pp.76-81.

[2] R. M. Lebron, J. L. Salazar, C. Fulton, D. Schmidt, S. Duthoit, R. Palmer, "A novel near-field robotic scanner for surface, rf and thermal characterization of millimeter-wave active phased array antenna," IEEE Int. Symp. Phased Array Systems \& Tech. (PAST), 2016, pp. 1-6.

[3] J. Richter, D. Nbtelt, F. Kloppel, J. Huck, H. Essent, L.-P. Schmidt, “A multi-channel radiometer with focal plane array antenna for W-band passive millimeter-wave imaging," IEEE MTT-S Int. Micro. Symp. Digest, 2006, pp. 1592-1595.

[4] B. Gonzalez-Valdes, Y. Álvarez, S. Mantzavinos, C. M. Rappaport, F. Las-Heras, J. Á. Martínez-Lorenzo, "Improving security screening," IEEE Ant. \& Prop. Mag., vol. 58, No. 4, 2016, pp. 35-47. 